\title{
Evaluation of Palliative Care Services Provided to Cancer Patients in the Gaza Strip
}

\author{
Bassam Abu Hamad ${ }^{1}$, Na'el Skaik ${ }^{2}$ and Hammoda Abu-Odah ${ }^{3}$ \\ 1. Department of Health Management, Al-Quds University, Gaza 00972, Palestine \\ 2. Department of Pharmacology, Al-Shifa Hospital, Gaza 00972, Palestine \\ 3. Department of Emergency, European Gaza Hospital, Rafah, Gaza 00972, Palestine
}

\begin{abstract}
Palliative care is designed to help patients to experience the best possible quality of life. The purpose of this study is to ascertain how far palliative care services are provided for cancer patients in Gaza. Patients treated at the oncology departments of three governmental hospitals had completed the Multinational Association of Supportive Care in Cancer/European Society for Medical Oncology (MASCC/ESMO), and PEACE international tool after introducing some modifications, and a twelve-item demographic questionnaire. A total of 374 respondents out of 396 (94.4\%) positively responded and participated in the study. The overall mean percentage of all items for all domains, which reflects the availability of palliative care, is $68.72 \%$, which means that the provided palliative care services are reasonably moderate. The medical aspect of care provided by physicians elicited the highest score (74\%); meanwhile, the nursing aspect of care scored less (68\%). Younger patients, whose malignancies were discovered at early stages and those who were treated in one single hospital, elicited higher scores with statistically significant differences in comparison to their counter groups. Despite being available, palliative care services are not well-framed in Gaza's hospitals. The study recommends that psychosocial care, home management and the adoption of multi-disciplinary team approach in palliative care require greater attention.
\end{abstract}

Key words: Palliative care, terminally ill cancer patients, end of life, Gaza governorates.

\section{Introduction}

According to the World Health Organization (WHO), cancer is ranked as the fourth cause of death in the Eastern Mediterranean Region, after cardiovascular diseases, infectious/parasitic diseases and injuries [1]. In addition, the largest increase in cancer incidence among the WHO regions in the next 15 years is likely to be in the Eastern Mediterranean Region, where projection models predict an increase of between $100 \%$ and 180\% [2]. In Palestine, currently, cancer is one of non-communicable diseases and is considered the second major cause of morbidity and mortality in the Gaza Strip (GS) after heart disease (representing 13\% of total deaths). Colorectal, breast, and lung cancers, and leukemia are the most common type of cancers among adults in the GS; treating these cancers makes high demands on cancer services [3].

Corresponding author: Hammoda Mohammed Abu-Odah, MPH., research field: public health.
Palliative Care (PC) is considered as one of services relevant to all life threatening diseases [4]. Cancer, one of these diseases that cannot always be cured completely, but definitely, a lot can be done to make the lives of oncology patients meaningful and productive. With this idea, the concept of PC was initiated and its valid for both highly resourced and low resourced countries, and is important at all stages of disease [5].

PC is an essential component of care delivery models designed to address healthcare reform mandates [6] and it enhances the quality of life and care of patients and their families and outcomes while reducing costs. In addition, $\mathrm{PC}$ is designed to help a person to experience the best possible quality of life as his/her cancer progresses. The focus of PC is not on dying or trying to find a cure. Instead, the focus is on living each remaining day as fully as possible [7].

Structurally, the Palestinian Ministry of Health 
provides the major bulk of secondary and tertiary oncology services through Al-Shifa, El-Rantisi and European Gaza hospitals. Moreover, the national health strategy document indicates that oncology services should be given a priority at different levels including prevention, control, management and follow up [3]. Due to the prevailing context characterized by closure, siege, limited resources and shortage of essential drugs, almost all patients in Gaza suffer. However, the literature indicates that the suffering of patients with cancer is even higher due to shortages of resources and the prevailing war-like context.

PC is not officially integrated in health care system in GS $[8,9]$. One study's findings illustrated the main problems in the region in lack of fund or governmental support, and lack of awareness for the need for such service among the public as well as the policy makers and professionals [10].

$\mathrm{PC}$ of cancer attracts a lot of clinical and research interest because of not only the high prevalence of cancer, but also because of the magnitude of care associated with the disease itself, its treatment, and the long duration of symptoms. However, little attention has been directed towards addressing and evaluation PC services in the GS, and previous studies conducted about these services are few in number and content, and mostly focused on cancer epidemiology. Some cancer care services are introduced, but there is little evidence as to whether these services are adequate or not. Moreover, there is a research gap in information about these services in GS and this gap in services needs special attention. Therefore, this study aimed to evaluate PC services delivered to cancer patients in the Gaza governorates.

\section{Research Methods}

\subsection{Design and Participants}

This is a cross-sectional study that was conducted on cancer patients registered at the oncology departments at three governmental hospitals in Gaza. From patients presented to oncology services related units, 374 patients were randomly selected, among them 353 agreed to voluntarily participate in the study, giving a response rate of $94.4 \%$.

\subsection{Sampling Size and Process}

Inclusion criteria for this study included being diagnosed with cancer and receiving health services from one of the three designated hospitals at least for one year. According to the inclusion criteria and using the Survey System 10-Evaluation Edition, 396 patients were randomly selected (selected from 7142) and invited to participate in this study [11]. A systematic random sampling approach was followed and participants were selected proportionate to the number of served oncology population at the targeted hospitals.

\subsection{Data Collection}

The MASCC/ESMO survey of PC and PEACE Tool [12] was used in this study after introducing some modifications in order to ensure the appropriateness of the tool to the Palestinian context. The draft tool was validated by ten experts to ensure its content validity. Finally, the questionnaire consists of eleven core aspects of oncology care involving 138 items. The eleven multi-item scales covered the aspects of care pertaining to psychological, physical, social and health care aspects. In addition, it covers registration process, physicians' related aspects of care, laboratory services, nursing care, pharmaceutical related care, inpatient care, radiology and referral related services.

Data was collected through face-to-face interviews with patients and also from patients' files and records. For children less than 12 years, caregivers were interviewed. At the start, all questionnaire forms were prepared, organized and classified with serial numbers to ensure the availability of the needed information. Four well-trained data collectors conducted data collection. Two training sessions were held that focused on interviewing techniques, selection of participants, and clarification of the instrument item by item and standardizing the implementation. At the data 
collection stage, participants were informed about the study purpose and procedures and informed consent was obtained. Data collection team informed participants about the research purpose, confidentiality of information with great care to maintain privacy and confidentiality. Participants were informed that their responses would not negatively influence the care they are currently receiving at the facility. Data collectors informed patients about their right to withdraw or to refuse participation. Filling each questionnaire took about 20 minutes on average.

\subsection{Validity and Reliability}

Reliability and the internal consistency of the questionnaire were assessed by Cronbach's alpha. Table 1 demonstrates that the total reliability test was as high as 0.927. In addition, general measures of reliability and validity such as standardization of the implementation, training of data collectors, ongoing checking and follow up were maintained. At each stage of the data collection and management, quality control checks were administered.

\subsection{Data Management and Statistical Analysis}

The collected data was analyzed using the Statistical Package for Social Sciences version 20 (SPSS Inc., Chicago, IL, USA). The analysis of data involved reviewing the filled questionnaires, developing data entry model, coding the questions, data entry and data cleaning. Nominal and ordinal scale data was reported as absolute and relative frequency, and normally distributed data was presented as means \pm standard deviation.

Recoding was done as needed for continuous variables and for amalgamating certain categories. Scale related questions pertaining to the perceptions about PC domains were computed and transformed into scores. For each domain and by using account order in the SPSS, the positive perception questions are represented as "yes $=1$ ", and "no $=2$ " for negative perception questions. Then the percentage was derived and frequencies of the numeric variables were conducted as percentages.

To determine any differences between the independent study variables with the total and sub-scores of the perceptual level, data was analyzed by the chi square test, correlation, independent sample t-test and one-way ANOVA. $P$ value $<0.05$ was considered as statistically significant.

\subsection{Data Management and Statistical Analysis}

An ethical approval was obtained from Helsinki Committee in Gaza to carry out the study. An administrative approval was obtained from the Ministry of Health to conduct the study at the three designated hospitals. Every participant was provided with a full explanatory form attached to the questionnaire including the purpose of the study, assurance about the confidentiality of the information,

Table 1 Palliative care domains reliability.

\begin{tabular}{llll}
\hline Palliative care related domains & No. of cases & No. of items & Reliability (Cronbach's alpha) \\
\hline Physicians related issues & 374 & 20 & 0.875 \\
Radiology services & 374 & 3 & 0.949 \\
Inpatient departments & 374 & 5 & 0.899 \\
Lab services & 374 & 10 & 0.991 \\
Social aspects & 374 & 9 & 0.899 \\
Nurses related issues & 374 & 18 & 0.896 \\
Archiving/registration & 374 & 6 & 0.948 \\
Health care system aspects & 374 & 27 & 0.997 \\
Pharmacy services & 374 & 17 & 0.893 \\
Psychological aspects & 374 & 18 & 0.897 \\
Referral & 374 & 5 & 0.958 \\
Overall & 374 & 138 & 0.927 \\
\hline
\end{tabular}


instructions on how to respond to the questionnaire, and a statement indicating that participation is voluntary. Honesty was maintained during reporting and analysis of the data with respect to confidentiality and respecting of results. To protect the rights of children participants, their caregivers' approval in addition to the child approval was obtained.

\section{Results}

\subsection{Socio-demographic Characteristics}

Overall, we included 374 patients diagnosed with cancer including 270 (72.2\%) females and 104 (27.8\%) males. Age categorization revealed that around half of the participants (41.0\%) are above the age of 65 years, $35.0 \%$ between $35-54$ years and the rest were below the age of 34 years $(8.8 \%)$.

Patients from Gaza Governorate represented the highest proportion (36.6\%), while Rafah Governorate was the lowest $(12 \%)$. More than half of the respondents $(59.6 \%)$ reported attaining a secondary school education and about $21.1 \%$ reported holding post-graduate degree certificate. The majority $(73.5 \%)$ of participants were married. Regarding smoking, $87.4 \%$ were not smokers at the time of data collection. About $44.9 \%$ of respondents were housewives. With regard to working status before and after the disease occurrence, $21.4 \%$ of patients were working before disease occurrence, while after disease occurrence, $12.5 \%$ of them stopped working and only $8.3 \%$ were still working. Cancer was the leading cause of stopping working $(51 \%)$ as reported by patients who stopped working which subsequently affected their financial status and their physical activity. Table 2 demonstrates the participants demographic characteristics in details.

\subsection{Medical History}

Around half, (41.4\%) of the surveyed patients were diagnosed with breast cancer among all cancer types; yet it represented $57.4 \%$ of all cancers in females in this study.
Among the cancer patients, $41.4 \%$ were diagnosed in the year that proceeded data collection. Suffering from disease's symptoms was the way of initiating the diagnosis of patients among $60.7 \%$, while it happened by coincidence in $38 \%$.

A majority, (79.9\%) of the patients described the stage of their disease as a primary grade, while $15.5 \%$ regarded it as an intermediate grade. However, data collected from records revealed a different proportions,

Table 2 Characteristics of the study participants $(n=374)$.

\begin{tabular}{|c|c|}
\hline Variables & No. $(\%)$ \\
\hline \multicolumn{2}{|l|}{ Gender } \\
\hline Male & $104(27.8)$ \\
\hline Female & $270(72.2)$ \\
\hline \multicolumn{2}{|l|}{ Age } \\
\hline Less than 12 years & $57(15.2)$ \\
\hline $12-34$ & $33(8.8)$ \\
\hline $35-54$ & $131(35)$ \\
\hline 55 and above & $153(41)$ \\
\hline \multicolumn{2}{|l|}{ Governorate } \\
\hline North Gaza & $59(15.8)$ \\
\hline Gaza & $137(36.6)$ \\
\hline Middle & $58(15.5)$ \\
\hline Khanyounis & $75(20.1)$ \\
\hline Rafah & $45(12)$ \\
\hline \multicolumn{2}{|l|}{ Residency } \\
\hline Outside camp & $260(69.5)$ \\
\hline Inside camp & $114(30.5)$ \\
\hline \multicolumn{2}{|l|}{ Marital status } \\
\hline Married & $275(73.5)$ \\
\hline Not-married & $36(9.6)$ \\
\hline Less than 18 years old & $63(16.9)$ \\
\hline \multicolumn{2}{|l|}{ Qualification } \\
\hline Less than secondary school & $223(69.6)$ \\
\hline Secondary school & $72(19.3)$ \\
\hline Diploma and more & $79(21.1)$ \\
\hline \multicolumn{2}{|l|}{ Job } \\
\hline Housewife & $168(44.9)$ \\
\hline Employee & $71(19)$ \\
\hline Not applicable-child & $135(13.6)$ \\
\hline \multicolumn{2}{|l|}{ Income (\$) } \\
\hline Less than $250 \$$ & $71(19)$ \\
\hline $250-500 \$$ & $53(14.2)$ \\
\hline $500-750 \$$ & $35(9.4)$ \\
\hline More than $750 \$$ & $8(2.1)$ \\
\hline Not applicable & $207(55.3)$ \\
\hline
\end{tabular}


Table 3 Medical history of the study participants $(n=$ 374).

\begin{tabular}{|c|c|}
\hline Variables & No. $(\%)$ \\
\hline \multicolumn{2}{|l|}{ Diagnosis } \\
\hline Breast cancer & $155(41.4)$ \\
\hline Haematology & $58(15.5)$ \\
\hline Digestive system & $50(13.4)$ \\
\hline Gynaecology & $40(10.7)$ \\
\hline Urinary system & $23(6.1)$ \\
\hline Respiratory system & $16(4.3)$ \\
\hline Head and neck & $14(3.7)$ \\
\hline Thyroid & $11(3)$ \\
\hline Bone & $7(1.9)$ \\
\hline \multicolumn{2}{|l|}{ Date of diagnosis } \\
\hline One year ago In 2011 & $155(41.4)$ \\
\hline $2-3$ years ago & $108(28.9)$ \\
\hline More than 3 years ago & $111(27.9)$ \\
\hline \multicolumn{2}{|c|}{ How diagnosis was initiated initially by } \\
\hline Suffering & $227(60.7)$ \\
\hline Coincidence & $142(38)$ \\
\hline Routine exam & $5(1.3)$ \\
\hline \multicolumn{2}{|c|}{$\begin{array}{l}\text { Disease grade at diagnosis (beneficiary } \\
\text { recall based) }\end{array}$} \\
\hline Primary & $299(79.9)$ \\
\hline Intermediate & $58(15.5)$ \\
\hline Advanced & $16(4.3)$ \\
\hline I don't know & $1(0.3)$ \\
\hline \multicolumn{2}{|c|}{ Disease grade at diagnosis (record based) } \\
\hline Primary & $250(66.8)$ \\
\hline Intermediate & $73(19.6)$ \\
\hline Advanced & $51(13.6)$ \\
\hline \multicolumn{2}{|c|}{$\begin{array}{l}\text { Treatment modalities-Past treatment (recall } \\
\text { based) }\end{array}$} \\
\hline More than one type of treatment & $215(57.8)$ \\
\hline Chemotherapy & $120(32.3)$ \\
\hline Surgical & $26(7)$ \\
\hline Radiation & $6(1.6)$ \\
\hline Other (drugs) & $5(1.3)$ \\
\hline Total & $372(100)$ \\
\hline \multicolumn{2}{|l|}{$\begin{array}{l}\text { Treatment modalities within last } 3 \\
\text { months-recall or record based }\end{array}$} \\
\hline Chemotherapy & $205(56.6)$ \\
\hline Hormonal & $40(11)$ \\
\hline More than one type of treatment & $33(9.1)$ \\
\hline Radiation & $21(5.8)$ \\
\hline Surgical & $15(4.2)$ \\
\hline Psychological & $1(0.3)$ \\
\hline Others/drugs & $47(13)$ \\
\hline Total & $362(100)$ \\
\hline
\end{tabular}

$66.8 \%$ of patients were with primary grade, $19.6 \%$ as intermediate grade and $13.6 \%$ with advanced grade.

Regarding treatment modalities, $57.8 \%$ of the participants treated with more than one treatment approach, $32.3 \%$ were treated with chemotherapy and the others were treated using different modalities (surgical, radiological). Table 3 provides additional details about participants' medical history

\subsection{Perceptions about the Disease and Quality of Life}

Around half, (51.9\%) of participants described their health status as "good", 30.7\% described it as "not bad" and $17.4 \%$ as "bad". The majority, $78.3 \%$ of participants were satisfied with their health status. The vast majority of patients $(91.2 \%)$ were satisfied with the services they received.

Approximately, $77 \%$ of patients reported that their income was negatively affected after developing the disease and the most frequently reported reason was attributed to the treatment costs $(98.6 \%)$. Findings also show that $31 \%$ of the participants reported that their partner/spouse helped them in performing daily activities, $27.8 \%$ reported that sons/daughters helped them, $21.7 \%$ reported that parents helped and $19.5 \%$ reported that no one helped them in carrying out daily life activities.

Less than half, (41.6\%) of patients showed that the disease affected their work negatively; out of those, 95.2\% attributed that to diminished physical activity. Most of respondents (81.3\%) had experienced two and more symptoms related to the disease in the last 3 months. Experiencing symptoms occurred the most after the diagnosis as reported by $66.4 \%$ of respondents, $14.2 \%$ reported experiencing symptoms after receiving chemotherapy, $12.9 \%$ reported experiencing symptoms at different stages of their disease journey.

\subsection{Overall Perceptions of Palliative Care Domains}

The overall PC scores were $68.73 \pm 10.33$, a moderate level. The highest solicited level was related 
Table 4 Perceptions about the disease and quality of life (n = 374).

\begin{tabular}{|c|c|}
\hline Variables & No. $(\%)$ \\
\hline \multicolumn{2}{|l|}{ Perceptions about health status } \\
\hline Good & $194(51.9)$ \\
\hline Not bad & $115(30.7)$ \\
\hline Bad & $65(17.4)$ \\
\hline \multicolumn{2}{|l|}{ Satisfaction about health status } \\
\hline Yes & $293(78.3)$ \\
\hline No/not sure & $63(16.9)$ \\
\hline I don't know & $18(4.8)$ \\
\hline \multicolumn{2}{|l|}{ Cancer affects their income } \\
\hline Yes & $289(77.3)$ \\
\hline No & $85(22.7)$ \\
\hline \multicolumn{2}{|l|}{ How cancer affects income } \\
\hline Increase in the treatment costs & $285(98.6)$ \\
\hline Losing job & $2(0.7)$ \\
\hline Other & $1(0.35)$ \\
\hline Unable to work & $1(0.35)$ \\
\hline \multicolumn{2}{|l|}{ Person who helps in daily life } \\
\hline Partner & $116(31)$ \\
\hline Son & $104(27.8)$ \\
\hline Parents & $81(21.7)$ \\
\hline No one & $73(19.5)$ \\
\hline \multicolumn{2}{|l|}{ Cancer affects job } \\
\hline Yes & $165(44.6)$ \\
\hline No & $146(39.5)$ \\
\hline Not applicable (child) & $59(15.9)$ \\
\hline Total & $370(100)$ \\
\hline \multicolumn{2}{|l|}{ How cancer affects job } \\
\hline Diminished physical ability & $157(95.2)$ \\
\hline Stop work due to symptoms & $7(4.2)$ \\
\hline Psychological & $1(0.6)$ \\
\hline Total & $165(100)$ \\
\hline \multicolumn{2}{|c|}{ Symptoms experienced (last 3 months) } \\
\hline More than 2 symptoms & $304(81.3)$ \\
\hline One symptom & $43(11.5)$ \\
\hline No symptoms & $27(7.2)$ \\
\hline \multicolumn{2}{|l|}{ Onset of experiencing symptoms } \\
\hline After diagnosis & $247(66.4)$ \\
\hline Post chemotherapy & $53(14.2)$ \\
\hline More than one period & $48(12.9)$ \\
\hline Before diagnosis & $23(6.2)$ \\
\hline Post radiotherapy & $1(0.3)$ \\
\hline Total & $372(100)$ \\
\hline
\end{tabular}

to physicians' performance $(74.17 \pm 16.28)$, followed by radiology services $(69.25 \pm 25.76)$ and inpatient departments $(68.56 \pm 30.99)$. The lowest levels were related to referral services $(28.24 \pm 30.99)$, followed by psychological aspects $(56.63 \pm 17.58)$ and pharmacy services (58.71 \pm 12.19$)$ (Table 5).

Findings show that the mean score percentage for referral service was $28.24 \%$; the lowest perceived one. A majority, $(72.5 \%)$, of patients were experiencing referral to health premises outside the Ministry of Health. Only $28 \%$ of those patients thought that it was easy to be referred abroad and $44.3 \%$ of patients reported that the services at hospitals abroad were better than the local ones. Nearly half of the referred patients $(52.7 \%)$ preferred treatment abroad and $59.4 \%$ reported that referrals were not primarily due to lack of services locally. It seems that other reasons motivate clients to prefer referral abroad regardless of the availability of services locally and these need further investigations.

The psychological aspects got the second lowest mean score $(56.63 \%)$ which reflects that patients with cancer were still suffering and their psychological needs remain unmet. Still, psychological services are not integrated into the regular care provided to patients with cancer as reported by the majority of the study respondents (90.8\%). Of the total interviewed patients, $18 \%$ reported feeling depressed, shocked, and sad. In addition, $33.2 \%$ of patients were thinking about death. Large proportion (40.6\%) of patients were suffering

Table 5 Descriptive statistics of cancer patients' important points allocated to the eleven MASCC/ESMO and PEACE dimensions.

\begin{tabular}{lll}
\hline $\begin{array}{l}\text { Palliative care related } \\
\text { domains }\end{array}$ & $\begin{array}{l}\text { Items } \\
\text { number }\end{array}$ & $\begin{array}{l}\text { Cancer patients } \\
\text { Mean } \pm \text { SD }\end{array}$ \\
\hline Physicians related issues & 20 & $74.17 \pm 16.28$ \\
Radiology services & 3 & $69.25 \pm 25.76$ \\
Inpatient departments & 5 & $68.56 \pm 30.99$ \\
Lab services & 10 & $65.11 \pm 15.82$ \\
Social aspects & 9 & $65.00 \pm 15.00$ \\
Nurses related issues & 18 & $63.49 \pm 19.66$ \\
Archiving/registration & 6 & $60.74 \pm 13.53$ \\
Health care system aspects & 27 & $59.55 \pm 7.17$ \\
Pharmacy services & 17 & $58.71 \pm 12.19$ \\
Psychological aspects & 18 & $56.63 \pm 17.58$ \\
Referral & 5 & $28.24 \pm 21.88$ \\
Overall & 138 & $68.73 \pm 10.33$ \\
\hline
\end{tabular}


constantly from pain and waking up at night because of it. Around two thirds of the interviewed patients (64.7\%) reported feeling alienation and fear at the oncology clinic. The vast majority of patients (98.4\%) believed that faith in God "Allah" relieves their suffering. Around $81.5 \%$ of patients were trying to be strong to withstand cancer and $79.9 \%$ were having a feeling to fight cancer.

Regarding the health care system aspect, findings show that the mean score percentage was $59.55 \%$. The great majority of patients (98.4\%) had a commitment to clinic visits scheduled dates and follow up to avoid delaying their treatment. On the other hand, 77.2\% were visiting the clinic without appointment. The vast majority of patients reported that there were no home visits from the clinic staff in any situation; even if patients are unable to visit the clinic. Home services were not available as well; this is an important neglected area of PC services. With regard to nutrition, only $63.6 \%$ of patients felt that the physician is caring about their nutrition. The vast majority of patients $(88.2 \%)$ reported that no nutritionist is available in the clinic.

With regard to nurses-related care, the total score was $63.5 \%$, indicating that the patients' perceptions toward nursing domain are not as expected. The vast majority of those patients (85.9\%) perceived nurses as showing tender/caring behaviors, $77 \%$ of them thought that therapy was not delayed due to nurses' workload and around 39\% of patients received palliative care in the cancer clinics as symptomatic treatment.

Concerning radiology services, findings show that the mean score percentage was $69.25 \%$. Most patients $(80.6 \%)$ reported that radiology orders were made and around $78.8 \%$ of respondents thought that they received regular radiology follow up, while $46.3 \%$ of patients experienced radiology at the private sector.

Regarding pharmacy services, the mean score percentage was 58.71\%; reflecting relatively low perceptions towards the pharmacy services. Findings also show that only $47.2 \%$ of patients believed that drugs were available continuously in the pharmacy, but $60.6 \%$ of patients felt that chemotherapy was provided instead of palliative drugs. The vast majority (96.8\%) of patients felt that pharmacists were caring about patients indicating the presence of good communication with pharmacists. Around $31.3 \%$ of patients had experienced cutting off their treatment due to lack of drugs. Additionally, $24.5 \%$ of patients considered that pain-killers are the main drugs for them.

The inpatients departments got the third highest mean score $(68.5 \%)$ which reflects that patients with cancer had moderate positive perceptions about this service. The vast majority $(87.4 \%)$ of patients were experiencing admission to the cancer department. From those patients, $94.8 \%$ had improved after receiving therapy and around $86.2 \%$ of them thought that services met their needs. About $80.4 \%$ of the admitted patients received intravenous nutrition and $31.7 \%$ of those patients thought that department provided better services than the clinic. Usually, patients need admission when they receive chemotherapy regimens that need long period administration. Exhausted patients with bad health status need hospital admission to receive advanced, complete and comfortable treatment.

\subsection{Relationship between Demographic and Disease} Characteristics with Overall Perception about Palliative Care

Independent t-test and one-way ANOVA were used to explore differences in perceptions about the $\mathrm{PC}$ in reference to disease and characteristics variables (Table 6).

Our results in Table 6 showed no significant relationships between overall perceptions and marital status $(P>0.05)$. Patients less than 12 years old significantly revealed higher perception scores in comparison with patients older than 12 years of age ( $P$ $=0.010)$. Moreover, patients who had received the oncology service from one hospital reported significantly 
Table 6 Comparison of cancer patients demographic and disease characteristics with overall perception about palliative care $(n=374)$.

\begin{tabular}{|c|c|c|c|c|c|}
\hline Variables & $\mathrm{N}$ & $\begin{array}{l}\text { Total score } \\
\text { mean } \pm \text { SD }\end{array}$ & $\mathrm{t}$ & $\mathrm{F}$ & $P$-value \\
\hline \multicolumn{6}{|l|}{ Marital status } \\
\hline Married & 275 & $69.04 \pm 9.87$ & 0.946 & & 0.345 \\
\hline Not Married & 99 & $67.89 \pm 11.55$ & & & \\
\hline \multicolumn{6}{|l|}{ Age (years) } \\
\hline Less than 12 years & 57 & $72.20 \pm 786$ & 2.77 & & $0.010 *$ \\
\hline 12 years and more & 317 & $68.11 \pm 10.61$ & & & \\
\hline \multicolumn{6}{|l|}{ Type of cancer } \\
\hline Breast & 155 & $69.14 \pm 9.93$ & & 2.42 & $0.015^{*}$ \\
\hline Haematological & 58 & $71.08 \pm 9.02$ & & & \\
\hline Digestive & 50 & $65.59 \pm 11.68$ & & & \\
\hline Gynaecological & 40 & $66.14 \pm 11.91$ & & & \\
\hline Urinary System & 23 & $69.97 \pm 9.69$ & & & \\
\hline Respiratory System & 16 & $72.10 \pm 6.15$ & & & \\
\hline Head and Neck & 14 & $70.34 \pm 11.13$ & & & \\
\hline Thyroid & 11 & $61.92 \pm 11.78$ & & & \\
\hline Bone & 7 & $73.19 \pm 5.23$ & & & \\
\hline \multicolumn{6}{|l|}{ Disease grade } \\
\hline Primary & 250 & $72.94 \pm 5.62$ & & 94.33 & $0.000 *$ \\
\hline Intermediate & 73 & $60.86 \pm 12.98$ & & & \\
\hline Advanced & 51 & $59.36 \pm 11.32$ & & & \\
\hline \multicolumn{6}{|l|}{ Place of treatment } \\
\hline One hospital & 162 & $71.70 \pm 7.69$ & 5.007 & & $0.000 *$ \\
\hline More than one place & 212 & $66.47 \pm 11.48$ & & & \\
\hline
\end{tabular}

t: Independent t-test; F: One-way NOVA; * Statistically significant.

higher scores for overall perceptions than those who received services from more than one place $(P<0.002)$. Patients with bone cancer had significantly higher perception scores in comparison with other type of cancer $(P=0.015)$. In addition, patients with primary stage disease statistically significantly have higher scores than those with advanced grades $(P=0.000)$.

\section{Discussion}

The present study was designed to assess how far PC services are provided to patients with cancer in Gaza in order to promote the provision of adequate services to meet patients' needs. It is important to identify aspects of the services provided and areas of strength and areas of weakness in the provided PC service. This section therefore begins by presenting the characteristics and medical history of the study population, and ends with perception about the disease and PC domains.

\subsection{Characteristics of the Study Population}

In our study, the proportion of females presented for treatment was comparatively higher than males. This could be related to high prevalence of breast cancer among all cancer types in addition to the fact that breast cancer needs more attention: thus they require recurrent visiting to the clinic to contact the staff. Another important factor could be related to the physiological features of females where they are affected rapidly with the complications of cancer and the side effects of treatment. This could be aggravated with traditional norms that restrict females' access for screening therefore they are usually discovered at a progressive grade. Abed et al. [11], stated that specific cancer incidence rate among females was higher than the rate among males, 52 and 46 per 100,000 persons respectively. 
Cancer increased as age increased, our findings revealed that the highest incidence of cancer was found among patients whose age was 55 years and above. These results were similar with cancer registry data at Ministry of Health that showed a gradual increase in cancer rates by age [11]. Our results showed that more than half of the cancer patients reported having a secondary school education degree.

The Gaza Governorate has the highest proportion of cancer patients. This could be attributed to Al-Shifa Hospital, which is the main cancer care provider in GS offering services to patients from the North Governorate to the Mid Zone Governorate including Gaza Governorate. This finding was compatible with Abed et al [11]. This could also be attributed to documentation practices where the staff usually registers the cases with no specific address as cases from Gaza "the capital".

\subsection{Medical History}

Breast cancer represented the highest percentage among all cancer types. This may reflect the current high incidence rate of breast cancer in the population as shown in the cancer registry report [11]. Most of patients were diagnosed recently, so they require more follow up, investigations and treatment while older cases mainly need only follow up. Our data showed that most of patients were suffering from the disease's symptoms, which triggered initiating the diagnosis. This may reflect a weakness in health education programs, screening and primary prevention policies that the health system has to adopt.

Findings showed a gap between disease grade based on recall from patients and data obtained from their records. This gap may point to missing or not having enough information transmitted from the medical staff to patients. In other words, there is an obvious gap in informing clients and communicating with them. Similar studies in this context have also found a gap between diagnosis grade based on recall from patients and data obtained from their records [13, 14]. This calls for improving interaction and communication with patients who are in bad need for information to reduce their anxieties and stress level.

Chemotherapy was the major treatment line to manage patients within the last 3 months. Chemotherapy causes many adverse reactions such as alopecia and anemia. This flags the importance of providing appropriate management and psychosocial support to patients. Patients described other treatments as oral drugs including analgesics, antibiotics and perhaps they do not know if the oral drugs were chemotherapy or not.

Our findings show that more than half of patients received treatment and follow up at more than one place; local hospitals and referral abroad. Ministry of Health refers its patients abroad especially when the service is not available and for other reasons as well such as based on family requests. This also complicates the situation, as patients with cancer had to receive their follow up in more than one place with its associated extra costs such as travel costs, problems related to handling off by different providers and lack of integration and continuity of care among the different providers. In particular, travel difficulties and complexities had bad impact on the patients because travelling abroad costs money for the patient him/herself, his/her relatives and for the Ministry of Health, and it exhausts already tired patients. Travel by itself is a source of suffering for Palestinians from Gaza given the siege and travel restrictions imposed on the entire population including the patients. In addition, the need for referral raises important questions about the availability of comprehensive integrated services at Ministry of Health premises and or inside Gaza.

\subsection{Perceptions about the Disease and Quality of Life}

More than half of cancer patients described their health status as "good", and the majority of them were satisfied with their health status. These perceptions might be related to cultural beliefs of accepting the realities, as they are, and regarding it as out of their 
control - externalist orientation of people "from God". The vast majority of patients are satisfied with the provided services. The same result was observed in a study conducted in the GS, which found that the overall patients' level of satisfaction with the quality of health services was $63.9 \%$ [15]. Income was affected after the disease and the most frequently reported cause was an increase in the treatment costs. A similar result was observed in two studies conducted about the impact of cancer diagnosis on income $[16,17]$. In addition, the disease affected work negatively which is in agreement with studies that presented that the disease affects patients' jobs negatively [18-20].

Most of cancer patients experienced two and more symptoms in the last three months, mostly pain. This may indicate the difficulties in controlling symptoms and pain in health care sector or a failure of the palliative treatment. More than half of patients were suffering from symptoms after diagnosis of cancer, so it was important to start PC from the time of diagnosis as most of the patients were suffering more at diagnosis stage and the health care staff should not underestimate the symptoms or patients' need at that critical period. This calls for paying more attention from the medical staff to the needs of clients, managing the symptoms and improving the quality of life. This is consistent with the previous studies [21, 22], which call for focusing on reducing pain and symptoms and improving the psychological wellbeing of clients at the early stage of the disease.

\subsection{Overall Perceptions of Palliative Care Domains}

The overall perception of PC level is moderate among cancer patients and the highest level was with physician's related issues. Similar findings illustrated the effectiveness of medical care that physicians provided which was sufficient as reported by patients [23]. In addition, about two-thirds of cancer patients showed difficulties to contact the physician once needed. Noting that WHO (2007) illustrated the crucial role of physicians in the PC. In countries with low number of physicians in a cancer clinic, it was unrealistic to apply PC completely [24]. About one-third of cancer patients thought that the waiting time was long at the physician's. These results were similar to another local study [25].

Most patients reported that radiology orders were made and they thought that they received regular radiology follow up, while nearly half of patients experienced radiology at the private sector. Bone scan and radiotherapy are still not available at Ministry of Health premises and these services are purchased by Ministry of Health from other facilities. Some patients received radiation as a palliative treatment to control cancer complications.

Usually, patients needed admission when they receive chemotherapy regimens that need long period administration. Exhausted patients with bad health status needed hospital admission to receive advanced, complete and comfortable treatment. WHO recommended that a specialized $\mathrm{PC}$ team is an effective way of providing PC services to inpatients in a variety of health-care settings. This team is typically composed of a physician trained in palliative medicine, at least one clinical nurse and a part-time social worker, all supported by adequate administrative staff. The team provides advices on every aspect of PC without need for special beds [24].

Lab tests were available in departments as perceived by patients while others have to resort to private labs. Cancer lab tests are expensive and this will negatively affect the patient economic status. Most patients did not experience losing their lab tests as there was a clear system for lab orders' collection. Most of patients thought that their lab results were not delayed. Anaemia was one of the main conditions that affected patients with cancer especially who are receiving chemotherapy. PC services manage anaemia and correct it with supportive medicines and blood transfusions. This is in agreement with studies presenting that PC services decrease significantly the cost of Lab tests, pharmacy and intensive care [26]. 
There was a high percentage of patients still having negative impressions about Lab services especially those who were suffering from multiple sample collections and absence of sample transporters at the clinic.

Most patients had increased concerns toward the family and their families also did. The social culture in our country provides support and sympathy/empathy to vulnerable and sick people. Palestinian people, as other developing countries, prefer social relationships among them and this may somewhat compensate the role of social workers in the clinic. Once the diagnosis is made, the family and relatives provide spiritual support and help the patients. This is in agreement with a comprehensive study which presented that family was the place to talk about patients' feelings for most of patients [23]. Patients with cancer thought that cancer accelerated end of their lives and this increased their concerns about their families. Nearly half of patients lost some social relationships with friends or relatives because of sickness. This could be related to cessation of work. Also, most of those patients were females. Female with breast cancer may undergo mastectomy surgery followed by chemotherapy. Both of these treatment modalities increase the psychological and physiological complications. Alopecia and breast surgery affect the appearance of females causing them to avoid people and to prefer to stay alone. Patients established social relations with others in the clinic during receiving treatment and follow up. They shared their experiences and feelings and supported each other at least to pass the treatment time.

From the literature review, sharing information between care providers and patients' families was important for treatment program.

PC service needs well trained and experienced nurses to perform the functions required for this service. Patients perceptions toward nursing services are not as expected and patients perceived nurses as showing tender/caring behaviors. There were no home visits from nurses to patients and this is consistent with the comprehensive study [23]. Good nurses are characterized by specific attitudes, skills, and knowledge; they engage in person-to-person relationships, respect the uniqueness of patients, and provide support. Being professionally trained staff, equipped with skills and specialized nursing knowledge are important for effective nursing care. These characteristics nurtured patient well-being, which manifests as optimism, trust, hope, support, confirmation, safety, and comfort. This will enable the development of more comprehensive and practice-based views on good nursing care for such patients. These perceptions help to understand how nurses effectively make a difference in cancer patient care [27]. It could be argued that Ministry of Health should focus on improving nursing services if it is concerned with PC.

Patients' perceptions toward archiving services are not adequately satisfactory. Most patients thought that it was easy to get their medical records or files and thought that data/sheets were kept in the patient profile. Nevertheless, vast majority of patients indicated weak communication between health care providers and patients. There was no clear system to contact patients to know at least if he/she is still alive or not. Some families did not inform the clinic of the death of their patients and this influences the credibility of cancer registry data. Ministry of Health should review the data and patients' files periodically and coordinate with the Ministry of Interior to validate death certificates. Health system should implement a policy to keep in contact with patients and to provide support and help when needed for disable patients via home care or hospice care.

The lowest level of PC domain was referral abroad. This result is mainly attributed to complexities in the referral process and in getting the needed travel approval. Access to referral abroad is usually challenged by travel restriction, extra out of pocket costs, bureaucracy and lack of clear referral policies. However, it is important to note that referrals are not 
always issued due to lack of local services, but it seems that other reasons motivate clients to be referred regardless of the availability of services locally and these need further investigations. In comparison to Sharp and Timmons study [16], the researcher believed that referral abroad is difficult and expensive, especially in the worst economic and political situation in Gaza.

\section{Conclusion}

Cancer is one of non-communicable diseases and is considered the second major cause of morbidity and mortality in the GS after heart disease. Colorectal, breast, and lung cancers, and leukemia are the most common type of cancers among adults in the GS; treating these cancers makes high demands on cancer services. PC is considered one of these services and it is a key component of an overall cancer control plan and program. PC services should be linked to cancer treatment strategies in order to make the best use of scarce resources. This study aimed to evaluate PC services delivered to cancer patients in the Gaza governorates. This study showed that currently, there are no well-identified designated PC services; neither specific structure nor department is available for this service. Yet, some components relevant to the PC services are available and provided within the general oncology services. This implies that PC needs more attention. Even for patients who are not able to come to the clinic, there is no home visits' program and oncology staff members do not provide home services. In addition, findings revealed that more scores that are positive were found among younger age, married, those at the primary grade of their diseases and those who were treated in only one hospital than their counterparts and the variations between the two groups were statistically significant. This study result is helpful for developing recommendations for key informants in the Palestinian Ministry of Health to develop better PC service. Additionally, it might enhance health information system including documentation, data flow, archiving, and supporting cancer registry, and ensure the provision of adequate supply of palliative medicines and chemotherapy. Moreover, it is recommended that psychosocial care, home management and the adoption of multi-disciplinary team approach to PC are among areas that require greater attention.

\section{Acknowledgement}

The authors' thank Allah first for helping them every moment and during the study. The authors' thanks go to their study participants. We also appreciate health care staffs who work at the oncology departments and daily care units for their help in interviewing patients.

\section{References}

[1] World Health Organization. 2002. Global Burden of Disease. Geneva.

[2] World Health Organization. 2012. "Globocan 2012: Estimated Incidence, Mortality and Prevalence Worldwide in 2012." International Agency for Research on Cancer.

[3] Ministry of Health. 2013. Health Annual Report. Gaza, Palestine.

[4] Gomez-Batiste, X., Stjernsward, J., Espinosa, J., Martinez-Munoz, M., Trelis, J., and Constante, C. 2013. "How to Design and Implement Palliative Care Public Health Programmes: Foundation Measures. An Operational Paper by the WHO Collaborating Centre for Public Health Palliative Care Programmes at the Catalan Institute of Oncology.” BMJ Support Palliative Care 3 (1): 18-25.

[5] World Health Organization. 2014. Global Atlas of Palliative Care at the End of Life. Geneva.

[6] Verret, D., and Rohloff, R. M. 2013. "The Value of Palliative Care." Healthcare Financ Manage 67 (3): 50-4.

[7] American Academy of Family Physicians. 2009. "Cancer: Palliative Care." Accessed May 15, 2015 http://familydoctor.org/online/famdocen/home/common/c ancer/treatment/722.html.

[8] Khleif, M., and Imam, A. 2013. "Quality of Life for Palestinian Patients with Cancer in the Absence of Palliative-Care Service: A triangulated Study." The Lancet 382 (S23): 23.

[9] Bingley, A., and Clark, D. 2009. “A Comparative Review of Palliative Care Development in Six Countries Represented by the Middle East Cancer Consortium (MECC)." Journal of Pain and Symptom Management 37 (3): 287-96. 
[10] Khleif, A. 2010. "Workshop on Psycho-Oncology: Alleviation of Fear, Frustration and Sense of Loss through Non-Pharmacological Treatment Modalities, (Abstracts); Palliative Care Situation in Palestinian Authority." Journal of Pediatric Hematology Oncology 32: 18-20.

[11] Abed, Y., El Saka, B., Hamdan, Kh., Abo Saman, Kh., and Yaghi, H. 2010. Cancer Incidence in the Gaza Strip, Palestine (1998-2008). Cancer Registry: Palestine.

[12] Okon, T. R., Evans, J. M., Gomez, C. F., and Blackhall, L. J. 2004. "Palliative Educational Outcome with Implementation of PEACE Tool Integrated Clinical Pathway.” J. Palliat. Med. 7 (2): 279-95.

[13] Sikorskii, A., Wyatt, G., Tamkus, D., Victorson, D., Rahbar, H., and Ahn, S. 2012. Concordance between Patient Reports of Cancer-Related Symptoms and Medical Records Documentation: University of Texas Science Center. Texas: USA.

[14] Strömgren, A. S., Groenvold, M., Pedersen, L., Olsen, A. K., Spile, M., and Sjøgren, P. 2001. "Does the Medical Record Cover the Symptoms Experienced by Cancer Patients Receiving Palliative Care? A comparison of the Record and Patient Self-Rating." Journal Pain Symptom Management 21 (3): 189-96.

[15] Aljeesh, Y., and Alkariri, N. 2010. "Patients Satisfaction with the Quality of Health Services Provided at the Outpatient Department at Al-Shifa Hospital.” The Islamic University Journal 18 (2): 111-21.

[16] Sharp, L., and Timmons, A. 2010. The Financial Impact of Cancer Diagnosis. National Cancer Registry: Ireland.

[17] Bennett, J. A., Brown, P., Cameron, L., Whitehead, L. C., Porter, D., and McPherson, K. M. 2009. "Changes in Employment and Household Income during the 24 Months Following a Cancer Diagnosis." Support Care Cancer 17 (8): 1057-64.

[18] Park, J. H., Park, J. H., and Kim, S. G. 2009. "Effect of Cancer Diagnosis on Patient Employment Status: A Nationwide Longitudinal Study in Korea."
Psychooncology 18 (7): 691-9.

[19] Mehnert, A. 2010. Employment and Work-Related Issues in Cancer Survivors. Department of medical psychology: University Medical Center Hamburg-Eppendorf, Germany.

[20] Lindbohm, M. L., Kuosma, E., Taskila, T., Hietanen, P., Carlsen, K., Gudbergsson, S., and Gunnarsdottir, H. 2011. "Cancer as the Cause of Changes in Work Situation (a NOCWO Study)." Psychooncology 20 (8): 805-12.

[21] Deshields, T. L., Potter, P., Olsen, S., Liu, J., and Dye, L. 2011. "Documenting the Symptom Experience of Cancer Patients." Journal Support Oncol. 9 (6): 216-23.

[22] Huijer, H., Abboud S., and Doumit, M. 2012. "Symptoms Prevalence and Management of Cancer Patients in Lebanon." Journal of Pain and Symptom Management 44 (3): 386-99.

[23] Osse, B. H., Vernooij-Dassen, M. J., Schadé, E., de Vree, B., van den Muijsenbergh, M. E., and Grol, R. P. 2002. "Problems to Discuss with Cancer Patients in Palliative Care: A Comprehensive Approach." Patient Educ. Couns. 47 (3): 195-204.

[24] World Health Organization. 2007. Cancer Control: Knowledge into Action, WHO Guide for Effective Program: Palliative Care 2007. Geneva, Switzerland.

[25] Abou-Amer, W. 2012. "Cancer Prevention and Control. Evaluation of the strategy in Gaza Governorates." Master's thesis, Al Quds University.

[26] Morrison, R. S., Penrod, J. D., Cassel, J. B., Caust-Ellenbogen, M., Litke, A., Spragens, L., Meier, D. E., and Palliative Care Leadership Centers' Outcomes Group. 2008. "Cost Savings Associated with US Hospital Palliative Care Consultation Programs." Arch. Intern. Med. 168 (16): 1783-90.

[27] Rchaidia, L., Dierckx de Casterlé, B., De Blaeser, L., and Gastmans, C. 2009. "Cancer Patients' Perceptions of the Good Nurse: A Literature Review." Nursing Ethic. 16 (5): 528-42. 